\title{
७MONÇÕES
}

DOI: $10.30612 /$ rmufgd.v10i19.13411

\section{O Protagonismo do Mato Grosso Do Sul para a resiliência do Corredor Rodoviário Bioceânico}

\section{Mato Grosso do Sul's Protagonism for the Resilience of the Bio-Oceanic Road Corridor}

\section{El Protagonismo del Mato Grosso do Sul para la resiliencia del Corredor Vial Bioceánico}

\author{
Pedro Silva Barros \\ Doutor em Integração da América Latina pela \\ Universidade de São Paulo e técnico de \\ planejamento e pesquisa do \\ Instituto de Pesquisa Econômica Aplicada (Ipea), \\ Brasília, DF - Brasil. \\ Email:pedro.barros@ipea.gov.br \\ Orcid: https://orcid.org/0000-0003-1325-2461 \\ Julia de Souza Borba Gonçalves \\ Estudante de Doutorado em Relações \\ Internacionais pela Universidade de Brasília \\ (UnB) e pesquisadora do Instituto de Pesquisa \\ Econômica Aplicada (Ipea), Brasília, DF - \\ Brasil. \\ Email: julia.goncalves@ipea.gov.br \\ Orcid: https://orcid.org/0000-0002-3148-4808
}

Resumo: Desde dezembro de 2017, a governança regional de todos os projetos de integração de infraestrutura na América do Sul que envolvem mais do que dois países foi paralisada, exceto a do Corredor Rodoviário Bioceânico, rota entre Porto Murtinho (Mato Grosso do Sul) e os portos do norte do Chile, próximo ao trópico de Capricórnio. O objetivo deste artigo é analisar a perenidade do GT do Corredor Rodoviário Bioceânico já nascido em um momento de declínio da integração regional, com desintegração econômica-comercial, fragmentação política entre os países e crise das instituições de governança regional, especialmente no que se refere à infraestrutura. O principal argumento desta pesquisa é que a resiliência do Corredor Rodoviário Bioceânico se explica pelo poder de atração da demanda da região Ásia Pacífico, notadamente a China e pelo envolvimento ativo dos governos subnacionais em estabelecer a agenda junto aos governos centrais do Brasil, Paraguai, Argentina e Chile. Analisa-se com especial atenção a atuação do governo estadual Mato Grosso do Sul, único Estado da Federação diretamente envolvido no projeto. 


\begin{abstract}
South American governance in regional infrastructure projects that encompass more than three countries has been paralyzed since December 2017. However, this is not the case of the Bi-Oceanic Road Corridor: a route connecting Porto Murtinho (Mato Grosso do Sul) in Brazil to the northern ports in Chile through the Chaco region in Paraguay, and the Northwest of Argentina. The purpose of this article is to analyze the reasons behind the resilience in managing this project in the context of the crisis in regional integration, alongside the occurrence of economic and commercial disintegration, political fragmentation among countries, and the crisis of regional governance institutions, especially those related to infrastructure projects. Our central argument is that the resilience of the Bi-Oceanic Road Corridor stems from the demand attractiveness of the Asia Pacific region, notably China, and the active involvement of subnational governments in settling the agenda alongside the central governments of Brazil, Paraguay, Argentina, and Chile. We analyze closely the efforts of the state government of Mato Grosso do Sul since it is the only Brazilian subnational unit directly involved in this project.
\end{abstract}

Keywords: Bi-Oceanic Road Corridor; Mato Grosso do Sul; Paradiplomacy; Infrastructure.

Resumen: Desde diciembre de 2017, se han paralizado todos los proyectos de infraestructura regional de América del Sur en los que participan más de tres países, con la excepción del Corredor Vial Bioceánico, una ruta entre Puerto Murtinho (Mato Grosso do Sul) en Brasil y los puertos del norte de Chile, atravesando la región del Chaco en Paraguay y el Noroeste de Argentina. El objetivo de este artículo es analizar las razones de la resiliencia de la gestión de este proyecto, que se creó en un momento de declive de la integración regional, con desintegración económica y comercial, fragmentación política entre los países y crisis de las instituciones de gobierno regional, especialmente en lo que se refiere al tema de proyectos regionales de infraestructura. El principal argumento de esta investigación es que la resistencia del Corredor de la Carretera Bioceánica se explica por la participación activa de los gobiernos subnacionales en establecer la agenda junto a los gobiernos centrales. Se analiza con especial atención el caso de Mato Grosso do Sul, el único unidad subnacional brasileña directamente involucrada en el proyecto.

Palabras-clave: Corredor Vial Bioceánico; Mato Grosso do Sul; Paradiplomacia; Infraestructura.

Recebido em

21/01/2021.

Aceito em

24/08/2021. 


\section{INTRODUÇÃO}

O projeto do Corredor Rodoviário Bioceânico foi formalizado em 2015 com a criação do Grupo de Trabalho (GT) do Corredor Rodoviário Bioceânico. O objetivo desse projeto é viabilizar o desenvolvimento de regiões que não foram adequadamente incluídas nos processos de integração nacional e regional, como o é o caso do centro-oeste brasileiro, e fomentar a integração regional do centro-oeste da América do Sul, especialmente do estado do Mato Grosso do Sul ${ }^{1}$.

Tal projeto foi formalizado em 2015 e desde então vem acompanhando as transformações políticas na região sul-americana. As instâncias de integração e cooperação regional vem passando por períodos de instabilidades e fragmentação, como os esvaziamentos da União de Nações Sul-Americanas (Unasul) e da Comunidade de Estados Latino-Americanos e Caribehos (Celac), a criação do Grupo de Lima e do "Foro para el Progreso de América del Sur" (Prosul), assim como a atuação mais ativa da Organização dos Estados Americanos (OEA) e de seus mecanismos no gerenciamento de crises na região (Barros et al, 2020).

No que diz respeito ao funcionamento do Conselho Sul-Americano de Infraestrutura e Planejamento (Cosiplan), ligado à Unasul, a última reunião foi realizada em dezembro de 2017 durante a Presidência Pro Tempore argentina. A partir de 2018, iniciou-se o processo de esvaziamento da Unasul com a retirada da Colômbia da mesma e a suspensão da participação de Argentina, Brasil, Chile, Equador, Paraguai e Peru da Unasul, e em 2019 foi criado o Foro do Progresso para a América do Sul (Prosul).

A Infraestrutura Regional Sul-Americana (IIRSA) foi uma iniciativa impulsada pela política externa brasileira e formalizada após a Primeira Reunião de presidentes da América do Sul, visando promover a integração em infraestrutura na região. A IIRSA foi incorporada ao COSIPLAN em 2010, cuja principal transformação foi a definição político-estratégica dos projetos, envolvendo diretamente os governos (BARROS; PADULA; SEVERO, 2011). A IIRSA foi uma iniciativa audaz que contribuiu para designação de investimentos em projetos, criação de

\footnotetext{
Este artigo é parte do projeto de pesquisa "Integração Regional: o Brasil e a América do Sul” do Instituto de Pesquisa Econômica Aplicada (Ipea) e dá continuidade ao trabalho de pesquisa publicado no livro "Corredor bioceânico de Mato Grosso do Sul ao pacífico: produção e comércio na rota da integração sul-americana". O Instituto de Pesquisa Econômica Aplicada (Ipea) coordena, pelo Brasil, a Mesa 2 "Produção e Comércio" do GT Corredor Rodoviário Bioceânico.
} 
sistema público de informações, geração de consensos e coordenação política, mas que também enfrentou dificuldades em relação às questões de sustentabilidade, participação local e mecanismos inovadores de financiamento (CASTRO; CIMINI, 2020).

Nos últimos anos, fatores como a ascensão econômica da China na América Latina, a Operação Lava-Jato, a desaceleração econômica e emergência de governos com agendas econômicas liberais foram fatores que impactaram na agenda de integração em infraestrutura no âmbito da Unasul (VIRGA; MARQUES, 2020).

Apesar dessa situação de desmantelamento de organizações regionais e seus respectivos órgãos, o Corredor Rodoviário Bioceânico continuou promovendo reuniões até o presente e tem havido significativos avanços em relação aos seus objetivos. O presente artigo busca responder por que as reuniões vêm ocorrendo apesar da conjuntura de fragmentação política na região.

Trabalha-se com a hipótese que esta situação excepcional do Corredor Rodoviário Bioceânico se justifica pelo poder de atração da demanda da região Ásia Pacífico, notadamente a China, e pelo interesse e, consequentemente, o envolvimento e atuação dos entes subnacionais dos países que fazem parte do projeto.

Portanto, pretende-se examinar a perenidade do GT do Corredor Rodoviário Bioceânico diante das mudanças políticas e, consequentemente, mudanças no regionalismo na América do Sul e avaliar o protagonismo do Mato Grosso do Sul para que o GT Corredor Rodoviário Bioceânico, cujos trechos estavam previstos nos eixos do Cosiplan/IIRSA da Unasul, continue se reunindo e avançando na consecução das obras apesar da fragmentação da daquela.

O procedimento metodológico baseia-se na análise bibliográfica sobre paradiplomacia e temas relacionados, como política exterior, regionalismo, conformação territorial, e análise a partir de dados primários, os quais são: atas das reuniões do GT Corredor Rodoviário Bioceânico; declarações presidenciais dos países envolvidos no projeto; e posicionamentos de atores políticos brasileiros sobre o Corredor Rodoviário Bioceânico.

Buscou-se sistematizar os dados primários de forma que se evidenciassem o envolvimento dos entes subnacionais no GT de maneira contínua, as agendas que promovem, os interesses e, no caso brasileiro, como o Mato Grosso do Sul vem adotando uma postura mais ativa em relação à integração da infraestrutura regional e aos temas de política externa em geral. 
Além da Introdução e Considerações Finais, o artigo se estrutura em 3 seções: na primeira, discute-se a criação e desenvolvimento das reuniões do GT Corredor Rodoviário Bioceânico a partir de suas atas de reuniões, das declarações presidenciais e informes por parte dos países, sistematizando tais informações.

Na segunda, baseando-se na literatura sobre paradiplomacia, são examinados a atuação dos entes subnacionais do Brasil (Mato Grosso do Sul), Argentina (províncias do Noroeste), Chile (regiões do Norte) e do Paraguai (região ocidental), e os interesses em corredores bioceânicos para a integração regional, relacionando questões de política externa com particularidades geográficas das regiões mencionadas.

Na terceira parte, examina-se a atuação do Mato Grosso do Sul no Corredor Rodoviário Bioceânico, destacando as instituições e os atores políticos envolvidos no projeto.

\section{ANTECEDENTES E FORMAÇÃO DO GT CORREDOR RODOVIÁRIO BIOCEÂNICO}

Segundo Fernández e Espinoza (2004), o conceito de Corredores Bioeânicos envolve a realidade territorial, multimodalidade de inovações e políticas e estratégias de integração subregional. São projetos políticos estratégicos promovidos por atores diversos (os governos, as empresas transnacionais e a sociedade civil), os quais mobilizam organizações, sejam elas públicas, privadas ou sociais, por onde passam os trechos dos corredores.

O Corredor Rodoviário Bioceânico foi formalizado com a "Declaração de Assunção sobre Corredores Bioceânicos", de 2015, em que se institui o Grupo de Trabalho (GT) do Corredor Rodoviário Bioceânico. Neste documento, os presidentes definem o objetivo do GT de impulsionar a integração regional em infraestrutura e, desta forma, possibilitar a conexão física entre portos do Atlântico e Pacífico. Compõem os trechos do Corredor Rodoviário Bioceânico: Campo Grande - Porto Murtinho (Brasil) - Carmelo Peralta - Mariscal Estigarribia Pozo Hondo (Paraguai) - Misión La Paz - Tartagal - Jujuy - Salta (Argentina) - Sico - Jama Puertos de Antofagasta - Mejillones - Iquique (Chile) (ITAMARATY, 2015).

São trechos que já estavam incorporados na carteira de projetos do Conselho SulAmericano de Infraestrutura e Planejamento (Cosiplan) da Unasul e contemplados pelos Eixos de Integração e Desenvolvimento. Ademais, a criação do GT do Corredor Rodoviário 
Bioceânico ocorreu por iniciativa do governo chileno da época de promover a "Convergência na Diversidade" entre o Mercosul e a Aliança do Pacífico, de modo que os "eixos de integração e desenvolvimento do Cosiplan e, em especial, os Corredores Bioceânicos constituem ferramentas centrais e indispensáveis para materializar esse objetivo de interesse comum" (ITAMARATY, 2015).

Os estudos da Comissão Econômica para a América Latina e Caribe (CEPAL) sobre a aproximação desses blocos destacam a relevância dos corredores binacionais e transoceânicos para viabilizá-la (CEPAL, 2014, 2018). Apesar de não mencionar diretamente o GT do Corredor Rodoviário Bioceânico, este é o único corredor rodoviário existente e em discussão contínua desde 2015 (BARROS et al, 2020).

A “Declaração de Brasília sobre Corredores Bioceânicos" de 2017 reafirma o interesse de prosseguir com o projeto para aproximar o Mercosul e a Aliança do Pacífico, viabilizar a integração produtiva, gerar fluxos de comércios e investimentos, integrar territórios, e definir os trabalhos a serem realizados para as reuniões posteriores (ITAMARATY, 2017).

Desta forma, o Corredor Rodoviário Bioceânico é o projeto de infraestrutura que conta com duas declarações presidenciais (BARROS et al, 2020). As declarações refletem a conjuntura política regional, ao dar mais ênfase a uma organização regional específica em detrimento de outros espaços regionais. Por exemplo, na Declaração de 2015 "reiteram seu decidido compromisso com o progresso de integração regional, por meio das atividades no âmbito da Iniciativa para a Integração da Infraestrutura Regional Sul-Americana (IIRSA) e o Conselho de Planejamento da UNASUL (COSIPLAN)" (ITAMARATY, 2015). Já a Declaração de 2017, assinada alguns dias após a última reunião ministerial do Cosiplan em meio à crise da Unasul, os presidentes não fizeram menção à Unasul ou ao COSIPLAN, e restringiram-se a apresentar o "corredor rodoviário bioceânico demonstra, de forma concreta, como se pode promover a convergência do Mercosul com a Aliança do Pacífico" (ITAMARATY, 2017).

De 2015 até 2020, o GT do Corredor Rodoviário Bioceânico estabeleceu 5 Mesas de Trabalho: 1) Infraestrutura, Transporte e Logística; 2) Produção e Comércio; 3) Simplificação dos Procedimentos Aduaneiros; 4) Rede de Universidades; e 5) Turismo. As mesas refletem os interesses e atores que se mobilizam em torno de um projeto de infraestrutura e demonstram que este vai além da ideia de se tornar um corredor de exportação. 
Observa-se que, além da participação e interesses amplos no GT do Corredor Rodoviário Bioceânico, a presença de entes subnacionais reforça a hipótese de que os mesmos dão continuidade ao projeto ao se organizarem e mobilizarem em torno das regiões que serão beneficiadas pelas obras de infraestrutura. A atuação de entes subnacionais, principalmente Estados, demonstram como eles possuem capacidade decisória (ainda que limitada), apresentam demandas em negociações internacionais, e buscam influenciá-las de acordo com seus interesses (MARIANO; MARIANO, 2002).

\section{ATORES E SEUS RESPECTIVOS INTERESSES NO CORREDOR RODOVIÁRIO BIOCEÂNICO}

Tendo em vista a situação de excepcionalidade do Corredor Rodoviário Bioceânico e a hipótese adotada neste artigo, faz-se necessário basear a análise em estudos sobre paradiplomacia, política externa (com ênfase nos atores que influenciam o processo de formulação e decisão), assim como os conceitos "regionalismo" e "regionalização".

A paradiplomacia estuda o fenômeno da atuação de entes subnacionais na Política Internacional. Os estudos ganharam impulso em decorrência da intensificação da globalização, da crise do Estado e da emergência de novos atores em temas internacionais (ODDONE, 2016; ALVAREZ, 2019; JUNQUEIRA, 2019).

Outro marco dos estudos sobre paradiplomacia foi a obra de Panayotis Soldatos (1990), em que o autor elaborou um marco conceitual para compreender a atuação externa de entes subnacionais de Estados Federados. A paradiplomacia pode ser do tipo global ou regional, e as ações paradiplomáticas podem ser cooperativas (em conformidade com o governo federal) ou ações paralelas (com conhecimento do governo federal, mas sem monitoramento ou, até mesmo, conflitiva).

No caso do Corredor Rodoviário Bioceânico, cabe pontuar suas características a fim de compreender como se dá a atuação de entes subnacionais no mesmo. Primeiro, o Corredor Rodoviário Bioceânico é um projeto de integração física entre regiões distantes dos centros nacionais, portanto, a questão territorial e transfronteiriça são variáveis fundamentais para compreender a mobilização subnacional em torno de dito projeto. 
Segundo, trata-se um projeto que envolve duas Repúblicas Federativas (Argentina e Brasil) e duas Repúblicas Unitárias (Chile e Paraguai), em que o grau de descentralização dos Estados pode levar a maior autonomia dos entes subnacionais para promover a cooperação internacional.

No caso de Argentina, o artigo 124 da Constituição permite que as províncias assinem acordos internacionais, desde que estejam de acordo com as diretrizes de política externa. No Brasil, o termo "diplomacia federativa" surgiu em 1995 para evidenciar a crescente participação de entes subnacionais e, ao mesmo tempo, manter a centralidade da condução da diplomacia (visto que é um tema de competência do Itamaraty) (JUNQUEIRA, 2019).

Já a atuação dos entes subnacionais chilenos é vinculada às questões de política exterior, dada a concentração de competências nessa temática nas figuras do Presidente e Ministro de Relações Exteriores: cabem ao Ministério de Relações Exteriores (através da Direção de Fronteiras e Limites) e ao Ministério do Interior (através da Subsecretaria de Desenvolvimento Regional e Administrativo) a responsabilidade em matéria de temas fronteiriços (OVANDO, 2017). No Paraguai, a descentralização ocorreu concomitantemente ao processo de redemocratização do país com reforma constitucional de 1992, permitindo que departamentos e municípios pudessem assinar acordos de cooperação internacional, em que municípios adquiriram mais autonomia para celebrar acordos de assistência econômica em relação aos departamentos (ODDONE; HOURCADE, 2012).

Terceiro, o Corredor Rodoviário Bioceânico está relacionado aos aspectos da integração regional sul-americana em diferentes níveis, pois: a) atravessa períodos de maior aproximação entre os países para o de maior fragmentação das instâncias regionais, como o declínio da Unasul e a criação do Prosul; b) mobiliza governos subnacionais que já participavam da Zona de Integração do Centro-Oeste Sul-americano (Zicosur), uma organização de integração regional promovida por governos subnacionais; c) surge a partir da proposta de governos nacionais em 2015 no contexto de aproximação da Aliança do Pacífico-Mercosul, dois blocos de integração, principalmente no aspecto econômico

Nesse sentido, ao abordar o fenômeno da paradiplomacia no contexto da integração regional, destaca-se que, apesar de não contar com um arcabouço teórico próprio, a teoria neofuncionalista permitiu que se tivesse um olhar mais atento às dinâmicas ao interior dos 
Estados para compreender como atores domésticos (incluindo os governos subnacionais) atuam em matéria de integração regional e como influenciam a decisões do Estado (ODDONE, 2016).

Como argumentado, o Corredor Rodoviário Bioceânico também dialoga com e potencializa outras experiências de cooperação regional centrada nas unidades subnacionais, como a Zicosur. A Zicosur é uma iniciativa sub-regional de projeção à Bacia do Pacífico dos mercados de províncias (Argentina), departamentos (Bolívia, Paraguai, Paraguai e Uruguai), regiões (Chile) e estados (Brasil), e que conformam o território do Chaco Sul-Americano (SAFAROV, 2000).

Uma característica comum das províncias, departamentos, regiões e estados que participam da Zicosur é que são economias periféricas em relação aos centros econômicos do Mercosul. Tal isolamento geográfico faz com que aquelas busquem alternativas para potencializar o dinamismo econômicos, em que corredores bioceânicos se tornam projetos estratégicos para tal fim (CARLINO, VAIRAVÉ, 2010).

A Zicosur foi uma iniciativa da Secretaria de Integração Regional de Antofagasta (Chile) em 1997 para fomentar a inserção dos entes subnacionais do centro-oeste sul-americano no cenário internacional ao propor a ligação entre os portos do Atlântico e Pacífico (HOURCADE; ODDONE, 2012).

No quadro 1, sintetizaram-se as reuniões do GT realizadas desde sua criação até a última reunião, em outubro 2020 - esta, realizada virtualmente.

Quadro 1: Histórico das reuniões do GT

\begin{tabular}{c|c|c|c}
\hline \multirow{2}{*}{ Ano } & Data & Reunião & Local \\
\hline \multirow{2}{*}{2016} & maio & I & Antofagasta, Chile \\
\cline { 2 - 4 } & julho & II & Campo Grande/MS, Brasil \\
\cline { 2 - 4 } & outubro & III & San Salvador de Jujuy, Argentina \\
\hline \multirow{2}{*}{2017} & maio & IV & Assunção, Paraguai \\
\cline { 2 - 4 } & novembro & V & Antofagasta, Chile \\
\hline \multirow{2}{*}{2018} & junho & VI & Salta, Argentina \\
\hline \multirow{2}{*}{2019} & abril & VII & Assunção, Paraguai \\
\cline { 2 - 4 } & agosto & VIII & Campo Grande/MS, Brasil \\
\hline
\end{tabular}




\begin{tabular}{l|l|l|l}
\hline 2020 & outubro & IX & Chile (online) \\
\hline
\end{tabular}

Fonte: BARROS et al, 2020.

Das 8 reuniões presenciais, apenas 2 foram realizadas em uma capital (Assunção, Paraguai) e as demais foram realizadas nas regiões por onde passará o Corredor, ressaltando a característica de descentralização deste projeto. Nas reuniões, a participação dos governos subnacionais no nível intermediário também é significativa.

Quadro 2: Presença de atores subnacionais nas reuniões do GT

\begin{tabular}{|c|c|c|c|c|}
\hline & $\begin{array}{l}\text { Nível Mínimo } \\
\text { (Municipal) }\end{array}$ & \begin{tabular}{|c|} 
Nível Intermediário \\
(Departamentos, Estados, \\
Províncias, Regiões)
\end{tabular} & $\begin{array}{c}\text { Nível Máximo (governos } \\
\text { centrais) }\end{array}$ & Estado \\
\hline \multirow[t]{4}{*}{$\begin{array}{l}\text { III } \\
\text { Reunião }\end{array}$} & - & \begin{tabular}{|l|} 
Jujuy: Governador, Ministro \\
de Infraestrutura, Ministro \\
de Desenvolvimento \\
Econômico e da Produção, \\
Diretor Provicial de Obras \\
Viárias, Secretário de \\
Integração Regional e \\
Relações Internacionais. \\
Salta: Representante de \\
Relações Internacionais e \\
Diretor de Obras Viárias \\
\end{tabular} & $\begin{array}{l}\text { MRE, Ministério de Interior, } \\
\text { Obras Públicas e Moradia; } \\
\text { Ministério de Produção; } \\
\text { Ministério de Transportes; } \\
\text { Ministério de Segurança; }\end{array}$ & Argentina \\
\hline & - & $\begin{array}{l}\text { Secretaria de Infraestrutura } \\
\text { do MS. }\end{array}$ & MRE & Brasil \\
\hline & - & Intendente de Antofagasta & $\begin{array}{l}\text { Vice-Ministro; Embaixador; } \\
\text { DIRECON/SUBREI; Ministério } \\
\text { de Obras Públicas; Serviço de } \\
\text { Aduanas; Ministerio de } \\
\text { Interior e Segurança Pública }\end{array}$ & Chile \\
\hline & - & & MRE & Paraguai \\
\hline \multirow{4}{*}{$\begin{array}{c}\mathrm{V} \\
\text { Reunião }\end{array}$} & - & \begin{tabular}{|l|} 
Jujuy: Ministro de \\
Infraestrutura, Secretário de \\
Desenvolvimento Industrial \\
e Comercial, \\
\end{tabular} & MRE & Argentina \\
\hline & - & - & MRE & Brasil \\
\hline & - & - & MRE & Chile \\
\hline & - & - & MRE & Paraguai \\
\hline
\end{tabular}




\begin{tabular}{|c|c|c|c|c|}
\hline \multirow[t]{4}{*}{$\begin{array}{c}\text { VI } \\
\text { Reunião }\end{array}$} & - & $\begin{array}{l}\text { Secretaria de Integração } \\
\text { Regional e Relações } \\
\text { Internacionais (Jujuy); } \\
\text { Subsecretaria de Comércio } \\
\text { (Salta); Instituto de } \\
\text { Desarrollo Económico y } \\
\text { Productivo (Tucumán); } \\
\text { Direção de Aduanas (Salta e } \\
\text { Jujuy). }\end{array}$ & $\begin{array}{l}\text { Subsecretário de } \\
\text { Infraestrutura; Ministério da } \\
\text { Segurança, Direção Nacional } \\
\text { de Migrações. }\end{array}$ & Argentina \\
\hline & - & SEINFRA (MS) & $\begin{array}{l}\text { MRE, Ministério de } \\
\text { Transportes, }\end{array}$ & Brasil \\
\hline & $\begin{array}{l}\text { Municipalidad } \\
\text { de Calama }\end{array}$ & Gobernación del Loa & $\begin{array}{l}\text { MRE; direcon; Servicio } \\
\text { Agrícola y Ganadero, }\end{array}$ & Chile \\
\hline & - & - & \begin{tabular}{|l|} 
MRE, Ministério de Obras \\
Públicas e Comunicações, \\
Direção Nacional de Aduanas, \\
\end{tabular} & Paraguai \\
\hline \multirow{4}{*}{$\begin{array}{c}\text { VII } \\
\text { Reunião }\end{array}$} & - & Provincia de Salta. & $\begin{array}{l}\text { Ministério do Interior, } \\
\text { Planificação Territorial } \\
\text { Nacional, } \\
\end{array}$ & Argentina \\
\hline & - & - & MRE & Brasil \\
\hline & $\begin{array}{l}\text { Municipalidad } \\
\text { de Alto } \\
\text { Hospicio, } \\
\text { Municipalidad } \\
\text { de Calama. } \\
\end{array}$ & $\begin{array}{l}\text { Governo Regional de } \\
\text { Antofagasta. }\end{array}$ & $\begin{array}{l}\text { MRE, Servicio Agrícola e } \\
\text { Ganadero, Serviço de Aduana, } \\
\text { Serviço Nacional de Turismo, }\end{array}$ & Chile \\
\hline & - & - & $\begin{array}{l}\text { MRE, Ministério de Obras } \\
\text { Públicas e Comunicações, } \\
\text { Ministério de Industria e } \\
\text { Comércio Exterior, Secretaria } \\
\text { Nacional de Turismo, }\end{array}$ & Paraguai \\
\hline \multirow{4}{*}{$\begin{array}{c}\text { VIII } \\
\text { Reunião }\end{array}$} & - & Provincia de Tucumán & MRE & Argentina \\
\hline & $\begin{array}{l}\text { Prefeitura de } \\
\text { Campo Grande; } \\
\text { Prefeitura de } \\
\text { Jardins. }\end{array}$ & $\begin{array}{l}\text { Secretaria de Estado de } \\
\text { Meio Ambiente, } \\
\text { Desenvolvimento } \\
\text { Econômico, Produção e } \\
\text { Agricultura Familiar, } \\
\text { Assessoria da bancada } \\
\text { parlamentar do MS. }\end{array}$ & $\begin{array}{l}\text { MRE, Ministério de } \\
\text { Infraestrutura, Ministério da } \\
\text { Agricultura, Pecuária e } \\
\text { Abastecimento, Agência } \\
\text { Nacional de Transportes, } \\
\text { Itaipú Binacional, }\end{array}$ & Brasil \\
\hline & - & $\begin{array}{l}\text { Representante da Região de } \\
\text { Tarapacá }\end{array}$ & MRE & Chile \\
\hline & - & - & $\begin{array}{l}\text { MRE, Ministério de Interior, } \\
\text { Ministério de Indústria e } \\
\text { Comércio Exterior, }\end{array}$ & Paraguai \\
\hline
\end{tabular}

Fonte: Elaboração dos autores com base nos documentos fornecidos pelo Itamaraty e no esquema elaborado por Junqueira (2019). 
No Quadro 2, sistematizaram-se os atores presentes nas reuniões do GT desde sua criação. Além de representantes dos governos subnacionais e de governos centrais, participaram também outros representantes vinculados às regiões por onde passa o corredor: do Puerto Antofagasta, representantes do complexo portuário de Mejillones, representantes da Administração Nacional de Navegação e Portos (Paraguai), e as Universidades: Universidade Federal do Mato Grosso do Sul, Universidad Nacional (Paraguai), Universidad Católica del Norte (Chile), Universidade Estadual do Mato Grosso do Sul, Universidade Católica Dom Bosco-MS, Universidade Federal da Integração Latino-Americana, Universidad Nacional de Jujuy (Argentina).

Considerando as características da conformação institucional do GT Corredor Rodoviário Bioceânico, constata-se que diversos atores privados; representantes de universidades; governos subnacionais (Municipalidades e Estados/Províncias/Regiões) e governos centrais participam das reuniões para discutir os mais variados temas: Universidades, turismo, procedimentos aduaneiros, temas agrícolas, sanitários etc.

Observa-se, portanto, que o GT Corredor Rodoviário Bioceânico é um projeto de infraestrutura que mobiliza diversos atores subnacionais e, também, privados em torno da ideia de que uma determinada região do território nacional será beneficiada.

Os projetos de infraestrutura que compõem o Corredor Rodoviário Bioceânico têm o potencial de integrar e desenvolver áreas isoladas nacionalmente e regionalmente, as quais podem ser caracterizadas como atrasadas economicamente: o noroeste da Argentina, o Chaco paraguaio, o norte do Chile e o Centro-Oeste brasileiro. Adicionalmente, o Corredor Rodoviário Bioceânico busca integrá-las a área de maior dinamismo econômico global, a região Ásia-Pacífico, que envolve o sudeste asiático e a costa oeste dos EUA.

Como visto no Quadro 2, o GT Corredor Rodoviário Bioceânico é um projeto de infraestrutura que mobiliza diversos atores. No que diz respeito aos representantes dos governos centrais, funcionários do Ministério de Relações Exteriores dos quatro países sempre estiveram presentes nas reuniões. Isso demonstra a relevância Corredor aos interesses da política externa dos países, seja em temas de integração regional ou de inserção 
global. Dessa forma, é possível afirmar que a atuação dos entes subnacionais é caracterizada como "ações paradiplomáticas cooperativas".

A principal iniciativa chinesa de integração global de infraestrutura é a Belt and Road Initiative (BRI), que inclui mais de cinco dezenas de países para ligar a China à África e à Europa. Para a sua execução foi criado o Asian Infrastructure Investiment Bank (AllB). Embora o Brasil seja considerado sócio fundador desse banco (PIRES; PAULINO, 2017), o país decidiu em outubro de 2016, no início do governo Michel Temer (2016-2018) reduzir drasticamente seu aporte inicial ao banco, de 3,18 bilhões de dólares para 5 milhões de dólares, sendo o mais baixo aporte entre todos os membros da instituição. A decisão foi mantida pelo governo Jair Bolsonaro (2019-) e aprovada pelo Senado Federal em 2020 (SENADO FEDERAL 2020a).

O Corredor Ferroviário Bioceânico, projeto que prevê a criação da ferrovia que conectará o Atlântico ao Pacífico passando por Brasil, Bolívia e Peru, recebeu atenção da China para receber investimentos como parte da iniciativa de incluir os países da América Latina na BRI (OLIVEIRA, MYERS, 2020).

De fato, o Corredor Ferroviário Bioceânico é comumente citado bibliografia sobre infraestrutura, porém é o Corredor Rodoviário Bioceânico que vem adquirindo mais viabilidade na sua consecução enquanto projeto de integração física - o que se pode atribuir ao caráter multidimensional (temas abordados no GT) e multinível (atores participantes) do projeto.

Nos anos recentes, a consecução de obras de infraestrutura tem se destacado na cooperação China-América Latina, concentrando-se no setor da infraestrutura: rodovias, pontes, infraestrutura de portos, hidroelétricas e termoelétricas (GRANSOW, 2015). De acordo com o China Global Investment Tracker (CGTI), os investimentos diretos chineses no Brasil se concentraram, nos setores de energia (36\%), transporte (21\%), metais (7\%) e agricultura (6\%) de 2010 a 2017 (TEIXEIRA, ROSSI, 2020).

\section{O PROTAGONISMO SUL-MATO-GROSSENSE PARA A RESILIÊNCIA DO CORREDOR RODOVIÁRIO BIOCEÂNICO}


Localizado no centro-oeste brasileiro, o Mato Grosso do Sul tem posição estratégica para ligar os oceanos Atlântico e Pacífico por se localizar no "coração continental" da América do Sul. É o único ente federado do Brasil que está diretamente envolvido no projeto do Corredor Rodoviário Bioceânico, enquanto nos demais países participam 3 ou mais entes subnacionais (regiões, departamentos e províncias).

Segundo Mariano e Mariano (2002, p. 48), o “Estado subnacional é uma organização formal com limites territoriais, população e funções definidas (...) Ao mesmo tempo, o Estado subnacional é integrante de um sistema mais amplo, o nacional, que o limita e influencia nessa função". Em relação à integração regional, os autores argumentam que um Estado subnacional se reporta à estrutura do governo federal, se uma determinada política adotada no Mercosul o prejudica, para conseguir compensações, ou busca adaptar-se a fim de minimizar perdas.

Nos últimos anos as exportações brasileiras e, com mais intensidade, sul-matogrossenses têm se deslocado para a Ásia Pacífico. Historicamente o comércio exterior do Mato Grosso do Sul foi um apêndice das exportações dos estados vizinhos atlânticos (São Paulo e Paraná). $\mathrm{O}$ aumento das exportações para o Pacífico abre possibilidade inédita de tornar o Mato Grosso do Sul um centro logístico médio, com relativa autonomia. Esse potencial mobiliza o empresariado, a estrutura governamental e os políticos locais. De acordo com Fernández e Espinoza (2004, p.159), os corredores:

\footnotetext{
Tienden a desarrollar innovaciones sociales e institucionales, (...) estas políticas recomiendan y orientan las innovaciones en métodos, técnicas e instrumentos de gestión apropiados a la realidad local y territorial; señalan líneas de acción y favorecen el cambio inducido por las innovaciones en el nivel local, con la natural consecuencia del fomento y el aumento de la competitividad.
}

A conformação de corredores para exportação de produtos, modernização de serviços logísticos e de portos, assim como a integração do Centro-Oeste brasileiro àqueles é uma ideia presente na definição de obras de infraestrutura desde os Planos Nacionais de Desenvolvimento da década 1970, passando pela concepção dos corredores logísticos de transporte da década de 1980, pelos Eixos Nacionais de Integração e Desenvolvimento da década de 1990, pela criação da IIRSA e os Eixos de Integração e Desenvolvimento até a incorporação destes ao Cosiplan em 2009 (LE BOURLEGAT, 2019). 
A relação entre política externa e integração regional em infraestrutura se observa, como já argumentado, desde a I Reunião de Presidentes Sul-Americanos. O BNDES foi o mecanismo financiador para impulsionar o projeto desenvolvimentista brasileiro na região através da IIRSA, em que empresas brasileiras recebiam financiamento para realizar obras de infraestruturas nos países vizinhos, e que foi facilitado pela dinâmica intergovernamental e interpresidencialista dos mecanismos regionais (NEVES, 2020).

Nesse sentido, as obras de infraestrutura para o Mato Grosso do Sul respondem à seguinte lógica:

\begin{abstract}
Ao conectar as regiões mediterrâneas do subcontinente sul-americano entre si e aos portos do Atlântico e, especialmente, do Pacífico, as obras de infraestrutura do Corredor Rodoviário Bioceânico permitem a redução dos custos logísticos e de transporte entre os países que o integram e, ao mesmo tempo, das exportações de produtos para fora da região. Também potencializaria a criação de Cadeias Regionais de Valor, assim como a melhor inserção dos países do Corredor nas Cadeias Globais de Valor (Barros et al, 2020, p. 13).
\end{abstract}

As relações entre o Brasil e a China se intensificaram entre 2000 e 2015, no marco da cooperação sul-sul, principalmente nas áreas de comércio, investimentos, infraestrutura, cooperação em instâncias regionais (Foro China-Celac) e multilaterais (BRICS, BASIC) (PIRES, 2015). As relações comerciais entre os dois países são superavitárias ao Brasil. Uma análise setorial, porém, indica que as importações brasileiras da China são concentradas em produtos industrializados e mais de $90 \%$ das exportações do Brasil esse parceiro se resumem a quatro produtos básicos: soja, minério de ferro, petróleo e celulose ${ }^{2}$. Soja, minério de ferro e óleo vegetal são os principais produtos do Mato Grosso do Sul exportados à China, a qual é 1으 destino das exportações sul-mato-grossenses desde 2007 (BRUM; AMORIM, 2016).

Cooperação transfronteiriça e integração regional sul-americana são temas presentes na agenda do Mato Grosso do Sul: o estado possui 7 cidades gêmeas (6 com o Paraguai e 1 com a Bolívia), participa da ZICOSUR, do Conselho de Desenvolvimento e Integração Sul (CODESUL), e as cidades de Bela Vista, Coronel Sapucaia, Dourados e Paranhos integram a Rede Mercocidades do Mercosul (BANZATTO, 2016). O caso das cidades gêmeas é de

20 número 24 da Revista Tempo do Mundo, do Ipea, disponível em https://www.ipea.gov.br/revistas/index.php/rtm/issue/view/23, traz três artigos que tratam especificamente das relações comerciais entre Brasil e China de petróleo, soja e minérios. 
particular interesse, pois são arranjos fronteiriços onde há um intenso fluxo econômico, comercial e cultural, ao mesmo tempo que são vulneráveis à circulação de ilícitos (PÊGO et al, 2020)

Na política externa recente, o Mato Grosso do Sul tem papel relevante nas principais agendas do governo. Atualmente, é um dos estados com maior peso nas relações Brasil-China que em 2020 respondeu por 45\% das exportações do Estado (SEMAGRO, 2021). Como um dos objetivos do Corredor é o acesso ao Pacífico, evidencia-se as facilidades que o Corredor traria ao comércio exterior com a China.

Nesse sentido, a influência desse estado serve como contrapeso aos setores notadamente anti-China do governo brasileiro. Não apenas o vice-presidente, Hamilton Mourão, mas também a atual ministra da Agricultura, Pecuária e Abastecimento, Tereza Cristina, desempenham o papel de "contrapeso" das declarações sinofóbicas. A retórica antiChina é marcada pelo discurso anticomunista e acaba por privilegiar (e justificar) o alinhamento com os EUA. Após a posse de Bolsonaro, ele "alterou a sua política em relação à China, passando a ser tutelado pelos setores que dão forte sustentáculo ao seu governo, além dos militares, que também foram afirmativos a favor de boas relações econômicas com a RPC" (ALMEIDA, 2020).

No que diz respeito ao Corredor Rodoviário Bioceânico, o envolvimento do Mato Grosso do Sul é notável. Apesar de não contar com Secretaria de Relações Internacionais própria, as duas instâncias que se ocupam de temas internacionais é o Conselho Extraordinário de Relações Nacionais e Internacionais para o Desenvolvimento Econômico de Mato Grosso do Sul (CONEX) e a Assessoria para os Assuntos do Conselho de Desenvolvimento e Integração (ASSESUL) (PRADO, 2013). No caso do Corredor Rodoviário Bioceânico, a Secretaria de Estado de Meio Ambiente, Desenvolvimento Econômico, Produção e Agricultura Familiar (SEMAGRO) vem desempenhando a função de Secretaria de Relações Internacionais do estado (SEMAGRO, 2020).

A organização do GT do Corredor é respaldada por duas Declarações Presidenciais específicas e suas atividades presenciais não ocorreram nas capitais nacionais (exceto Assunção, capital mais próxima ao Corredor), mas sim nas capitais das províncias, regiões e 
estado dos países que integram o projeto. No caso do Brasil, as duas reuniões do GT realizadas no país foram em Campo Grande, capital do Mato Grosso do Sul, em que o governo estadual teve um grande protagonismo. Além da organização e da presença das mais altas autoridades do estado, o próprio website oficial do Corredor Rodoviário Bioceânico ${ }^{3}$ tem o domínio registrado pelo Governo do Mato Grosso do Sul. Nesse website, estão as apresentações dos anos de 2016 (II reunião) e 2019 (VIII reunião), em que o estado sediou as reuniões do GT (CORREDOR BIOCEÂNICO, 2020).

Em relação à mesa 4 "Rede de Universidades" o protagonismo e respaldo institucional do estado do Mato Grosso do Sul se evidencia. A rede é composta por 12 universidades dos quatro países, sendo seis brasileiras, todas do Mato Grosso do Sul. Há universidades públicas e privadas, mas a liderança é da única ligada ao governo local. A Universidade Estadual do Mato Grosso do Sul (UEMS) se destacando sobre as demais instituições que fazem parte da Mesa Universidades do GT. Partiu da UEMS a iniciativa de redatar o estatuto, de criar o website da Rede de Universdades (Unirila) (ITAMARATY, 2020) e de oferecer um curso de pósgraduação lato sensu em Transporte Logístico e Direito Aduaneiro (UEMS, 2020).

Já o protagonismo dos políticos locais em relação ao Corredor tem sido importante tanto para a manutenção das atividades do GT do Corredor como para a viabilização das obras de infraestrutura relacionadas ao projeto. O Senador Nelson Trad Filho (PSD-MS) é o parlamentar mais ativo na defesa do Corredor Rodoviário Bioceânico. Trad é presidente da Comissão de Relações Exteriores e Defesa Nacional (CRE) do Senado desde 2019, presidente da representação brasileira no Parlamento do Mercosul e coordenador da bancada federal de Mato Grosso do Sul.

Se compararmos a quantidade de vezes que o Senado Federal e a Câmara de Deputados abordaram o tema nas comissões das respectivas casas, observa-se que o Corredor Rodoviário Bioceânico tem sido discutindo com mais frequência no Senado Federal, onde Trad

3 Disponível em: https://www.corredorbioceanico.ms.gov.br/. O mais novo website com informações do corredor, lançado neste segundo semestre de 2020, está sob domínio do governo regional da Região de Antofagasta, quando as atividades da IX Reunião do GT estão sendo organizadas pelo Chile em modo virtual. Disponível em: https://corredorbioceanico.org/. 
preside a CRE, do que na Câmera Federal: no primeiro, discutiu-se tanto em sessões próprias sobre o tema quanto em sabatinas com os futuros embaixadores do Brasil nos postos do exterior (CÂMARA DE DEPUTADOS, 2020; SENADO FEDERAL, 2020b). No Senado, o tema também foi discutido em outra comissão, o que não ocorre na Câmara: a senadora Simone Tebet (MDB-MS) pautou o tema do Corredor Rodoviário Bioceânico na Comissão de Assuntos Econômicos (CAE) (SENADO FEDERAL, 2018).

Já a ministra Cristina é deputada federal licenciada por Mato Grosso do Sul e tem sua trajetória política voltada pela defesa agronegócio, seja na Frente Parlamentar da Agropecuária, na Secretaria do Desenvolvimento Agrário do Mato Grosso do Sul e em sua formação como engenheira agrônoma.

Sua atuação como contrapeso em momentos de ofensiva da política externa atual pode ser observada nos momentos de crise com países árabes (devido ao anúncio de transferir a embaixada brasileira de Tel Aviv a Jerusalém), com os países europeus devido às queimadas na Amazônia e com a China, alvo de críticas de apoiadores bolsonaristas (SCHELP, 2020). Cabe também destacar a "diplomacia do agronegócio" impulsionada pelo Itamaraty na política externa atual, na qual a ministra é entusiasta e esteve presente no seminário organizado pela Fundação Alexandre de Gusmão (FUNAG) sobre o tema (FUNAG, 2020).

Outro aspecto da relevância do estado em relação ao Corredor Rodoviário Bioceânico é que na VIII Reunião do GT, em Campo Grande, o ministro Araújo declarou ter conversado com o governador do Estado sobre a abertura de um escritório do Itamaraty no Mato Grosso do Sul para acompanhar o desenvolvimento daquele (ITAMARATY, 2019) o que foi confirmado mais adiante pelo então secretário-geral do Ministério das Relações Exteriores Otávio Brandelli em fevereiro de 2020 (CORREIO DO ESTADO, 2020). Ainda que a abertura do escritório do Itamaraty faça coro ao discurso de Araújo de que o Ministério das Relações Exteriores "tem que ser também o ministério das relações interiores", o anúncio da abertura do escritório no estado se dá no mesmo cenário da retração diplomática global com fechamento de representações diplomáticas brasileiras, embaixadas e consulados, em várias regiões do mundo (O GLOBO, 2020). 
O chanceler Ernesto Araújo, na reunião do GT de agosto de 2019, mencionou ser a primeira vez que visitava o estado do Mato Grosso do Sul e, sobre o Corredor Rodoviário Bioceânico, declarou:

Eu quero parabenizar todos os esforços que estão sendo feitos pelos demais governos e destacar os esforços que estão sendo feitos pelo governo brasileiro para permitir o avanço extraordinário desse projeto, conforme nós vimos aqui na apresentação do Senador Nelson Trad. Tivemos já, nesses quase oito meses dessa ação aqui no Brasil, um esforço muito intenso para que esse e outros projetos de infraestrutura, mas esse muito especialmente, pudesse começar a se tornar uma realidade, por exemplo, com o início das obras da ponte, a ser financiada pela Itaipu Binacional (ITAMARATY, 2019).

O conselheiro da Itaipu Binacional Carlos Marun é outra figura que vem agindo a favor do Corredor Rodoviário Bioceânico, seja no exercício do cargo atual ou na sua atuação parlamentar até 2018 (CAMPO GRANDE NEWS, 2020).

\section{CONSIDERAÇÕES FINAIS}

O GT do Corredor Rodoviário Bioceânico é o único projeto de infraestrutura que agrupa mais de dois países e que se reúne periodicamente apesar do movimento de fragmentação da região atualmente.

A excepcionalidade do Corredor, diante das mudanças políticas regionais, se explica por maior envolvimento dos entes subnacionais dos quatro países envolvidos. A realização das reuniões em cidades que não são capitais nacionais acaba por blindar o GT das mudanças de governos nacionais e fortalecem os interesses dos entes subnacionais envolvidos no Corredor Rodoviário Bioceânico, reforçados pelo fato de vivenciarem dinâmicas transfronteiriças.

No artigo, buscou-se evidenciar que a continuidade das atividades do grupo de Trabalho do Corredor Rodoviário Bioceânico se dá pelo potencial de fomentar o potencial logístico das regiões envolvidas, articulando os centros econômicos tradicionais dos respectivos países e seus vizinhos, e os mercados asiáticos, com destaque para a China. Consequentemente, acomoda-se demandas regionais e ações de políticos locais com as orientações nacionais de política externa. 
No caso do Mato Grosso do Sul, destacam-se a mudança do eixo comercial e mudança na percepção dos agentes econômicos do ente federado, assim como interesses pragmáticos dos políticos desse estado. A própria agenda do estado encontra eco nos Ministérios das Relações Exteriores e da Agricultura. Há envolvimento de senadores, ministros, conselheiros e representantes das Universidades que faz com que a agenda discutida no GT Corredor Rodoviário Bioceânico atenda as principais reivindicações logísticas e comerciais do estado.

\section{REFERÊNCIAS}

ALMEIDA, Jorge. Tapas e beijos: as relações Brasil-China no governo Bolsonaro. Disponível em: https://diplomatique.org.br/tapas-e-beijos-as-relacoes-brasil-china-no-governobolsonaro/. Acesso em: 19 jan. 2021.

BARROS, Pedro et al. Corredor bioceânico de Mato Grosso do Sul ao pacífico: produção e comércio na rota da integração sul-americana. Campo Grande: UEMS, 2020.

BARROS, Pedro; PADULA, Raphael; SEVERO, Luciano. A integração Brasil-Venezuela e o eixo Amazônia-Orinoco. Boletim de Economia e Política Internacional, n. 7, p. 33-41, 2011.

BANZATTO, Arthur. A paradiplomacia como instrumento de integração fronteiriça no Mercosul e a atuação do estado de Mato Grosso do Sul nesse contexto in: Lamoso, Lisandra (org.). Relações Internacionais de Mato Grosso Do Sul: Comércio, Investimentos e Fronteira. Curitiba: Íthala, p. 209-244. 2016.

BRUM, Adriana.; AMORIM, Gustavo. A inserção internacional de Mato Grosso Do Sul: uma análise pela pauta exportadora e importadora. In: Lamoso, Lisandra (Org.). Relações Internacionais de Mato Grosso Do Sul: Comércio, Investimentos e Fronteira. Curitiba: Íthala, p.15-39. 2016.

CÂMARA DOS DEPUTADOS. Busca: Corredor Rodoviário Bioceânico. 2020. Disponível em: https://www.camara.leg.br/busca-

portal?contextoBusca=BuscaGeral\&pagina=1\&order=relevancia\&abaEspecifica=false \&q=\%2 2corredor\%20rodovi\%C3\%A1rio\%20bioce\%C3\%A2nico\%22. Acesso em: 19 jan. 2021.

CAMPO GRANDE NEWS. Marun tem esperança de voltar para Itaipu após voto favorável em julgamento. Disponível em: https://www.campograndenews.com.br/politica/maruntem-esperanca-de-voltar-para-itaipu-apos-voto-favoravel-em-julgamento. Acesso em: 19 jan. 2021. 
CASTRO, Aline; CIMINI, Fernanda. El financiamiento de la integración infraestructural sudamericana: las dificultades institucionales de constitución de un nuevo arreglo financiero regional. Revista Tempo do Mundo, n. 23, p. 123-148, 2020.

CARLINO, Alicia; VEIRAVÉ, Federico. La formación de bloques subregionales: la provincia del Chaco y sus vínculos con los Estados del sur brasilero. Revista Ciclos en la historia, la economía y la sociedad, v. 37-38, n. 19, p. 51-75. 2010.

TEIXEIRA, Izabella; ROSSI, Tereza. Brasil e China: elementos para a cooperação em meio ambiente. Centro Brasileiro de Relações Internacionais (CEBRI), 2020. Disponível em: http://midias.cebri.org/arquivo/Relatorio_A4_PT_6jul.pdf. Acesso em: 19 jan. 2021.

CEPAL. La Alianza del Pacífico y el MERCOSUR: hacia la convergencia en la diversidad. Santiago de Chile: CEPAL, 2014.

CEPAL. La convergencia entre la Alianza del Pacífico y el MERCOSUR: enfrentando juntos un escenario mundial desafiante. Santiago de Chile: CEPAL, 2018.

CORREDOR BIOCEÂNICO. Disponível em: http://www.corredorbioceanico.ms.gov.br/. Acesso em: 19 jan. 2021.

CORREIO DO ESTADO. Itamaraty ganhará escritório em Campo Grande para discutir rota bioceânica. Disponível em: https://correiodoestado.com.br/cidades/itamaraty-ganharaescritorio-em-campo-grande-para-discutir-rota-bioceanica/367917. Acesso em: 19 jan. 2021.

EFE. Macri propone que China colabore con IIRSA para conectar Asia con Sudamérica. Disponível em: https://www.efe.com/efe/america/economia/macri-propone-que-chinacolabore-con-iirsa-para-conectar-asia-sudamerica/20000011-3266462. Acesso em: 28 maio 2020. 2017a.

FERNANDEZ, Luis; ESPINOZA, Augusta. Corredores bioceánicos: territorios, políticas y estrategias de integración regional. Análisis Económico, v. XIX, n. 41, p.153-174, 2004.

FUNAG. Seminário "Diplomacia do Agronegócio". Disponível em: http://funag.gov.br/index.php/pt-br/2015-02-12-19-38-42/2925-inscricoes-abertas-para-oseminario-diplomacia-do-agronegocio. Acesso em: 19 jan. 2021.

GRANSOW, Bettina. Chinese Infrastructure Investment in Latin America-an Assessment of Strategies, Actors and Risks. Journal of Chinese Political Science, v. 20, n. 3), p. 267-287, 2015.

ITAMARATY. Declaração de Assunção Sobre Corredores Bioceânicos. 21 dez. 2015. Disponível em: 
http://www.itamaraty.gov.br/images/ed_integracao/DeclaracionBioceanicos_PT.pdf. Acesso em: 19 jan. 2021.

ITAMARATY. Declaração de Brasília Sobre Corredores Bioceânicos. 21 dez. 2017. Notas à Imprensa. Disponível em: http://www.itamaraty.gov.br/pt-BR/notas-a-imprensa/18097atos-adotados-por-ocasiao-da-li-reuniao-do-cmc-e-da-li-cupula-de-chefes-de-estado-domercosul-e-estados-associados-brasilia-20-e-21-de-dezembro-de-2017. Acesso em: 19 jan. 2021.

ITAMARATY. Intervenção do Ministro Ernesto Araújo na VIII Reunião do Corredor Rodoviário Bioceânico - Campo Grande (MS), em 22 de agosto de 2019. Disponível em: http://www.itamaraty.gov.br/pt-BR/discursos-artigos-e-entrevistas-categoria/ministro-dasrelacoes-exteriores-discursos/20764-intervencao-do-ministro-ernesto-araujo-na-viii-reuniaodo-corredor-rodoviario-bioceanico-campo-grande-ms-em-22-de-agosto-de-2019. Acesso em: 19 jan. 2021.

ITAMARATY. Atas das reuniões do Corredor Rodoviário Bioceânico. 2020.

JUNQUEIRA, Cairo. Entre interesses e identidades, o que querem e o que são? A atuação internacional dos governos subnacionais argentinos e brasileiros no Mercosul (1995-2018). Tese de Doutorado em Relações Internacionais, Programa de Pós-Graduação em Relações Internacionais "San Tiago Dantas", 2019.

LAUFER, Rubén. Argentina y su asociación estratégica con China en la era Kirchner. Análisis y Pensamiento Iberoamericano sobre China, n. 22, p. 4-24. 2017.

LE BOULEGAT, Cleonice. Eixos de integração e desenvolvimento, rota de integraçao latinoamericana e turismo: território de Mato Grosso do Sul e franjas fronteiriças. Interações, n. 20(especial), p. 107-123, 2019.

MARIANO, Karina; MARIANO, Marcelo. As teorias de integração regional e os estados subnacionais. Impulso, v. 13, n. 31, p. 47-69, 2002.

ODDONE, Nahuel. La paradiplomacia desde cinco perspectivas: reflexiones teóricas para la construcción de una comunidad epistémica en América Latina. Revista Relaciones Internacionales, v. 89, n. 2, p. 47-81. 2016.

HOURCADE, O.; ODDONE, N. Gran Chaco Sudamericano. Un escenario privilegiado para la cooperación transfronteriza. Informe para Redes Chaco. 2012.

NEVES, Bárbara. O Paradoxo da Política Externa Brasileira: uma análise a partir da infraestrutura regional. Agenda Política, v. 8, n. 3, p. 221-256, 2020. 
OLIVEIRA, Gustavo; MYERS, Margaret. The Tenuous CoProduction of China's Belt and Road Initiative in Brazil and Latin America. Journal of Contemporary

China, DOI: 10.1080/10670564.2020.1827358.

O GLOBO. Itamaraty corta embaixadas e chama de volta $\mathbf{1 1 \%}$ dos diplomatas no exterior. Disponível em: https://oglobo.globo.com/mundo/itamaraty-corta-embaixadas-chama-devolta-11-dos-diplomatas-no-exterior-23717247. Acesso em: 19 jan. 2021.

PEGO, Bolívar et al (Orgs.). Fronteiras do Brasil: uma avaliação do Arco Central. Vol. 4. Brasília: Ipea, 2019.

PIRES, Marcos Cordeiro.; PAULINO, Luís. A. Reflexões sobre a hegemonia e a política internacional da China: a iniciativa "cinturão e rota" como uma estratégia de desenvolvimento pacífico. Relaciones Internacionales, n. 53, p. 207-228, 2017.

PIRES, Marcos Cordeiro. Notas Sobre A Parceria Estratégica Brasil - China. IN: SORIA, Adrian; MILET, Paz. (Orgs). China en América Latina y el Caribe: Escenarios estratégicos subregionales. San José: FLACSO, 2015, p. 249-275.

PRADO. Henrique. A paradiplomacia e Mato Grosso do Sul: o potencial do estado no ambiente internacional. RealizAção, v. 1, n. 1, 2013, p. 105-115.

SAFAROV, Alejandro. El Territorio como factor dinámico de la integración: La ZICOSUR. Revista Persona, 2000. Disponível em: http://www.revistapersona.com.ar/Persona21/21Safarov.htm. Acesso em: 19 jan. 2020.

SEMAGRO. Carta de Conjuntura. N. 62, 2021. Disponível em:

https://www.semagro.ms.gov.br/wp-content/uploads/2021/01/Setor-Externo-Dezembro2020.pdf. Acesso em: 19 jan. 2021.

SENADO FEDERAL. Retorno econômico do Corredor Bioceânico é unanimidade em audiência. 2018. Disponível em: https://www12.senado.leg.br/noticias/materias/2018/04/18/retorno-economico-docorredor-bioceanico-e-unanimidade-em-audiencia. Acesso em: 19 jan. 2021.

SENADO FEDERAL. Aprovada entrada do Brasil no Banco Asiático de Investimento em Infraestrutura. 2020a. Disponível em:

https://www12.senado.leg.br/noticias/materias/2020/08/05/aprovada-entrada-do-brasilno-banco-asiatico-de-investimento-em-infraestrutura. Acesso em: 01 jul. 2021.

SENADO FEDERAL. Busca: Corredor Rodoviário Bioceânico. 2020b. Disponível em: http://www6g.senado.leg.br/busca/?q=\%22corredor+rodovi\%C3\%A1rio+bioce\%C3\%A2nico \%22. Acesso em: 19 jan. 2021. 
SEMAGRO. RELAÇÕES INTERNACIONAIS. 2020. Disponível em:

https://www.semagro.ms.gov.br/Geral/relacoes-internacionais/. Acesso em: 19 jan. 2021.

SCHELP, Diogo. O que segura a ministra Tereza Cristina, da Agricultura, no cargo. Disponível em: https://noticias.uol.com.br/colunas/diogo-schelp/2020/04/27/o-que-segura-terezacristina-da-agricultura-no-cargo.htm. Acesso em: 19 jan. 2021.

UEMS. UNIRILA. Disponível em: http://www.uems.br/midiaciencia/unirila/. Acesso em: 19 jan. 2021.

VIRGA, Thais.; MARQUES, Tomás. A integração física sul-americana no período recente (2000-2020): situação, continuidade, inflexão e reversão. Revista Tempo do Mundo, n. 23, p. 149-180, 2020. 